\title{
PENENTUAN HARGA PREMI ASURANSI UNIT LINK DENGAN GARANSI MINIMUM
}

\author{
Ni Luh Putu Ratna Dewi ${ }^{1 \S}$, I Nyoman Widana ${ }^{2}$, Luh Putu Ida Harini ${ }^{3}$ \\ ${ }^{1}$ Program Studi Matematika, Fakultas MIPA - Universitas Udayana [Email: ratnadewi160897@gmail.com] \\ ${ }^{2}$ Program Studi Matematika, Fakultas MIPA - Universitas Udayana [Email: nwidana@yahoo.com] \\ ${ }^{3}$ Program Studi Matematika, Fakultas MIPA - Universitas Udayana [Email: ballidah@ gmail.com] \\ ${ }^{\S}$ Corresponding Author
}

\begin{abstract}
The goal of this research is to determine the pricing of unit-linked insurance after attaching the minimum guarantees, which are guaranteed minimum maturity benefit (GMMB) and guaranteed minimum death benefit $(G M D B)$ using the Black-Scholes-Merton Method. Before the new price is determined, the previous steps are find the value of $F_{n}$ and $h(n)$ for $G M M B$ or $F_{t}$ and $h(t)$ for GMDB. The result of pricing on the cases in this research, resulted if the new price included GMMB with the interest rate 6\% and management expenses $0 \%$ and $2 \%$ are changed from $R p 21.000 .000,00$ become $R p 21.003 .000,00$ and $R p$ 21.031.000,00. On the other hand, the new price for interest rates $14 \%$ and $20 \%$ with both management expenses are constant. Furthermore, the new price included GMDB with management expense $0 \%$ and $2 \%$ also interest rates $6 \%, 14 \%$, and $20 \%$ in succession are changed from $R p$ 21.000.000,00 become $R p$ 25.132.000,00; Rp 21.031.000,00; Rp 21.002.000,00; Rp 44.521.000,00; $R p$ 44.520.000,00 and $R p$ 44.520.000,00.
\end{abstract}

Keywords: Unit Linked Insurance, Pricing, GMMB, GMDB

\section{PENDAHULUAN}

Salah satu langkah paling lumrah dalam menjamin dan memproteksi berbagai aset dan kebutuhan sehari-hari adalah dengan mengikuti asuransi. Asuransi terdiri dari berbagai jenis, seperti asuransi jiwa, asuransi kesehatan, asuransi pendidikan, dan lain-lain. Menurut Rayvin (2015), asuransi jiwa merupakan asuransi yang paling diminati. Hal ini disebabkan oleh manfaatnya yang besar baik bagi pemegang polis maupun bagi ahli waris jika yang bersangkutan telah meninggal dunia.

Asuransi jiwa dapat dibedakan menjadi asuransi jiwa tradisional (asuransi jiwa berjangka, asuransi jiwa seumur hidup, asuransi jiwa dwiguna, dan asuransi jiwa tertunda) serta asuransi jiwa modern (asuransi jiwa universal, unitized with-profit life insurance, asuransi jiwa unit link). Asuransi jiwa unit link merupakan asuransi yang menawarkan manfaat ganda, yaitu proteksi dan investasi kepada pemegang polisnya.
Menurut Cristina dan Diana-Maria (2014) karena memiliki unsur investasi, asuransi unit link juga dipengaruhi oleh ketidakstabilan finansial akibat krisis global dan persaingan pasar. Salah satu upaya yang dapat dilakukan untuk mencegah kemungkinan terburuk dari tingkat pengembalian saham, asuransi ini juga disertai dengan garansi minimum. Beberapa jenis garansi minimum yang dapat ditawarkan di antaranya guaranteed minimum maturity benefit (GMMB) atau dalam istilah Indonesia dapat disebut garansi minimum manfaat jatuh tempo serta guaranteed minimum death benefit (GMDB) atau dalam istilah Indonesia diartikan sebagai garansi minimum manfaat kematian. Menurut Dickson (2009) perbedaan mendasar dari kedua jenis garansi minimum tersebut, yaitu dalam GMMB peserta pemegang polis akan mendapatkan nilai garansi pada masa jatuh tempo kontrak dengan catatan yang bersangkutan tetap hidup. Sedangkan, dalam GMDB nilai garansi akan diberikan jika 
pemegang polis meninggal dunia selama kontrak masih berlaku.

Langkah-langkah untuk melakukan perhitungan garansi minimum dalam asuransi unit link memiliki kesesuaian dengan perhitungan dalam opsi finansial. Dalam hal ini, opsi yang dimaksud adalah opsi jual (put) tipe Eropa. Adapun metode yang digunakan adalah Metode Black-Scholes-Merton, yaitu metode yang digunakan untuk menghitung opsi yang tidak disertai dividen. Berdasarkan uraian tersebut, tujuan dari penelitian ini adalah untuk mengetahui harga premi asuransi unit link yang disertai dengan pemberian garansi minimum (GMMB dan GMDB) beserta faktor yang memengaruhi harga premi baru tersebut.

Suatu garansi minimum diperlukan untuk melibatkan perusahaan asuransi terkait dalam pembagian risiko dari investasi produk asuransi tersebut. Menurut Hardy (2003), pembagian risiko tersebut dapat dikategorikan menjadi GMMB, GMDB, GMIB, GMSB, dan GMAB. Perhitungan nilai garansi tersebut memiliki kesesuain dengan perhitungan opsi tipe Eropa. Menurut Hardy (2013), bentuk opsi paling sederhana dapat dibedakan menjadi opsi beli (call) dan opsi jual (put). Opsi tersebut dapat dihitung dengan menggunakan beberapa metode, salah satunya adalah Metode Black-Scholes-Merton. Opsi beli dapat dihitung menggunakan persamaan

$c(t)=S_{t} \Phi\left(d_{1}(t)\right)-K e^{-r(T-t)} \Phi\left(d_{2}(t)\right)$.

Sedangkan, opsi jual dihitung berdasarkan persamaan

$$
p(t)=K e^{-r(T-t)} \Phi\left(-d_{2}(t)\right)-S_{t} \Phi\left(-d_{1}(t)\right) .
$$

Bentuk garansi minimum yang banyak diberikan adalah garansi minimum manfaat jatuh tempo (GMMB) dan manfaat kematian (GMDB). GMMB merupakan garansi yang dibayarkan pada akhir masa jatuh tempo kontrak dengan catatan pemegang polis tetap hidup. Sebaliknya, GMDB akan diberikan kepada pemegang polis saat yang bersangkutan meninggal dunia selama kontrak masih berlaku. Menurut Dickson (2009) nilai akhir dari suatu opsi dapat dihitung menggunakan persamaan berikut

$$
h(n)=\max \left(\bar{P}-F_{n}, 0\right)
$$

dengan $\bar{P}$ didefinisikan sebagai jumlah dari premi tunggal dengan nilai GMMB yang diberikan atau dapat ditulis sebagai

$$
\bar{P}=P+\pi_{M}(0)
$$

Selanjutnya, nilai dari GMMB dihitung berdasarkan persamaan berikut ini.

$$
\pi_{M}(0)={ }_{n} p_{x} E_{0}^{Q}\left[e^{-r n} h(n)\right]
$$

Lambang $Q$ dalam persamaan (3) menyatakan ukuran risiko netral dan ${ }_{n} p_{x}$ merupakan peluang orang yang berusia $x$ tahun akan mencapai usia $x+n$ tahun.

Di lain pihak, untuk sebuah garansi berjangka $n$ tahun berlaku apabila pemegang polis meninggal dunia pada usia $x+t$ dengan $t<n$, maka nilai GMDB yang harus disiapkan perusahaan dihitung berdasarkan persamaan berikut.

$$
v(0, t)=E_{t}^{Q}\left[e^{-r n} h(t)\right]
$$

dengan $h(t)$ didefinisikan sebagai

$$
h(t)=\max \left(\bar{P} e^{r t}-F_{t}, 0\right)
$$

$F_{t}$ dalam persamaan (5) menyatakan nilai dana unit pemegang polis pada saat $t$ yang didefinisikan sebagai

$$
F_{t}=\bar{P} S_{t}(1-m)^{12 t}
$$

dan $\bar{P}$ merupakan harga premi baru yang didefinisikan sebagai

$$
\bar{P}=P+\pi_{D}(0)
$$

Peluang densitas kematian pada usia $x+t$ tahun dapat dinyatakan sebagai ${ }_{t} p_{x} \mu_{x+t}$, sehingga nilai GMDB dapat dihitung dengan mencari rerata seluruh peluang meninggal pada usia $x+t$. Menurut Dickson (2009), jumlah dana yang harus disiapkan juga dapat dihitung menggunakan persamaan berikut.

$$
\pi_{D}(0)=\int_{0}^{n} v(0, t){ }_{t} p_{x} \mu_{x+t}
$$

Namun, jika GMDB dibayarkan pada akhir bulan dari kematian yang bersangkutan, maka perhitungan GMDB akan mengikuti formula berikut ini.

$$
\pi_{D}(0)=\left.\sum_{j=1}^{12 n} v\left(0, \frac{j}{12}\right)_{j-\frac{1}{12}}\right|_{\frac{1}{12}} q_{x}
$$

Dengan kata lain, perhitungan GMDB dalam asuransi unit link dilakukan dengan menggunakan persamaan (9).

\section{METODE PENELITIAN}

Penelitian ini menggunakan data sekunder, yaitu peluang kematian berdasarkan tabel mortalita Indonesia tahun 2011, data hasil investasi CARLink Pro Mixed dengan premi tunggal Rp 21.000.000,00 yang diperoleh dari PT AJ Central Asia Raya. Tingkat bunga investasi 
yang digunakan yaitu 6\%, 14\%, 20\% dengan suku bunga bebas risiko (BI rate) sebesar 6\% serta biaya pengelolaan dana peserta masing-masing $0 \%$ dan $2 \%$. Masa kontrak yang digunakan adalah 45 tahun dengan usia pemegang polis 30 tahun.

Adapun langkah penelitian yang dilakukan adalah sebagai berikut.

1. Menghitung volatilitas berdasarkan data historis.

a. Menghitung return dari hasil investasi CARLink Pro Mixed dengan persamaan $R_{t}=\ln \left(\frac{S_{t}}{s_{t-1}}\right)$

b. Menentukan expected return dengan persamaan $E\left(R_{t}\right)=\frac{1}{n} \sum_{t=1}^{n} R_{t}$

c. Menghitung volatilitas historis berdasarkan persamaan

$\sigma=\sqrt{n\left[\frac{\sum_{t=1}^{n}\left(R_{t}-\overline{R_{t}}\right)^{2}}{n-1}\right]}$

2. Menghitung opsi jual tipe Eropa menggunakan metode Black-Scholes-Merton.

a. Menghitung nilai dana unit pemegang polis pada waktu $t\left(F_{t}\right)$

b. Menentukan nilai opsi akhir dari GMMB menggunakan persamaan (1).

c. Menentukan nilai opsi akhir dari GMDB menggunakan persamaan (5).

d. Menghitung $d_{1}(0, t)$ dan $d_{2}(0, t)$ untuk GMMB dan GMDB menggunakan persamaan

$$
\begin{aligned}
& d_{1}(t)=\frac{\log \left(\frac{S_{t}}{K}\right)+\left(r+\frac{\sigma^{2}}{2}\right)(T-t)}{\sigma \sqrt{T-t}} \\
& d_{2}(t)=d_{1}(t)-\sigma \sqrt{T-t}
\end{aligned}
$$

e. Menghitung nilai distribusi normal standar untuk $d_{1}(0, t)$ dan $d_{2}(0, t), \Phi\left(-d_{1}(0, t)\right)$ dan $\Phi\left(-d_{2}(0, t)\right)$.

f. Menghitung nilai $v(0, t)$ untuk GMDB berdasarkan persamaan (4).

3. Menentukan harga premi asuransi unit link setelah diberikan garansi minimum.

a. Menghitung nilai $\pi_{M}(0)$ berdasarkan persamaan (3).

b. Menentukan harga premi baru untuk GMMB menggunakan persamaan (2).

c. Menentukan peluang kematian yang tertunda, ${ }_{t-\frac{1}{12}} \mid \frac{1}{12} q_{x}$.

d. Menghitung nilai $\pi_{D}(0)$ berdasarkan persamaan (8). e. Menentukan harga premi asuransi baru untuk GMDB menggunakan persamaan (7).

\section{HASIL DAN PEMBAHASAN}

Sebelum mengetahui masing-masing harga premi baru akan dijabarkan perhitungan mengenai GMMB dan GMDB untuk asuransi unit link, dalam hal ini adalah CARLink Pro Mixed dengan premi tunggal Rp 21.000.000, biaya administrasi $7,15 \%$, suku bunga bebas risiko $6,5 \%$, tingkat bunga investasi masing-masing $6 \%, 14 \%$, dan $20 \%$ serta biaya pengelolaan sebesar $0 \%$ dan $2 \%$.

Manfaat asuransi tersebut yang akan diterima oleh pemegang polis, yaitu

1. Apabila pemegang polis tetap hidup sampai usia 75 tahun, maka yang bersangkutan akan menerima nilai investasi sebesar nilai dana unit yang dimiliki.

2. Apabila pemegang polis meninggal dunia sebelum usia 75 tahun, maka yang bersangkutan akan menerima nilai investasi sebesar nilai dana unit yang dimiliki dan uang pertanggungan sebesar Rp 21.000.000,00.

Langkah-langkah perhitungan yang dilakukan, yaitu:

1. Menghitung volatilitas berdasarkan data historis.

a. Menghitung return dari hasil investasi menggunakan persamaan (10) dan data hasil investasi CARLink Pro Mixed tahun 2014 2018.

Untuk $t=1$,

$$
\begin{aligned}
R_{1} & =\ln \left(\frac{S_{1}}{S_{1-1}}\right) \\
\Leftrightarrow R_{1} & =\ln \left(\frac{S_{1}}{S_{0}}\right) \\
& =\ln \left(\frac{2.652 .097}{2.606 .366}\right) \\
& =0,0173937 .
\end{aligned}
$$

Perhitungan untuk $t$ yang lain dilakukan dengan cara yang sama.

b. Menentukan expected return menggunakan persamaan (11).

$$
\begin{aligned}
\overline{R_{t}} & =\frac{1}{n} \sum_{t=1}^{n} R_{t} \\
& =\frac{0,0173937+0,0122306+\cdots+0,0191147}{58} \\
& =0,0022844 .
\end{aligned}
$$


Dengan demikian, expected return dari investasi pada asuransi unit link tersebut adalah 0,0022844 .

c.Menghitung volatilitas historis dengan persamaan (12).

Terlebih dahulu dihitung nilai dari $\left(R_{t}-\overline{R_{t}}\right)^{2}$. Untuk $t=1$,

$$
\begin{aligned}
\left(R_{1}-\overline{R_{t}}\right)^{2} & =(0,0173937-0,0022844)^{2} \\
& =0,000228 .
\end{aligned}
$$

Setelah mendapatkan $\left(R_{t}-\overline{R_{t}}\right)^{2}$ untuk semua $t$, maka volatilitas historisnya dihitung sebagai berikut.

$$
\begin{aligned}
\sigma & =\sqrt{n\left[\frac{\sum_{t=1}^{n}\left(R_{t}-\overline{R_{t}}\right)^{2}}{n-1}\right]} \\
\sigma & =\sqrt{58 \times\left[\frac{0,0002283+0,000099+\cdots+0,000283}{58-1}\right]} \\
\sigma & =\sqrt{0,0185185} \\
\sigma & =0,136=13,6 \% .
\end{aligned}
$$

Dari sini diperoleh bahwa volatilitas historisnya adalah $13,6 \%$.

2. Menghitung opsi jual tipe Eropa.

a. Menghitung nilai dana unit pemegang polis.

Menurut Dickson (2009) nilai dana pemegang polis untuk GMMB didefinisikan sebagai berikut.

$$
F_{n}=\bar{P}(1-e)(1-m)^{n-1} \frac{S_{n}}{S_{0}}
$$

Asumsikan $S_{0}=1$, maka persamaan (14) menjadi

$$
F_{n}=\bar{P}(1-e)(1-m)^{n-1} S_{n}
$$

Selanjutnya, untuk mempermudah penulisan nilai $(1-e)(1-m)^{n-1}$ disebut dengan $\xi$, sehingga persamaan (15) dapat ditulis kembali sebagai

$$
F_{n}=\bar{P} \xi S_{n}
$$

Di lain pihak, nilai dana unit untuk GMDB diberikan oleh formula berikut.

$$
F_{t}=\bar{P} S_{t}(1-m)^{12 t}
$$

b. Menentukan nilai opsi akhir dari GMMB dan GMDB.

Nilai opsi akhir untuk GMMB $\left(h_{n}\right)$ diperoleh dengan mensubstitusikan persamaan (16) ke dalam persamaan (1) sehingga menghasilkan

$$
h(n)=\max \left[\bar{P} \xi\left(\xi^{-1}-S_{n}\right), 0\right]
$$

Dari sini diperoleh bahwa harga tebus $(K)$ adalah $\xi^{-1}$. Selanjutnya, berdasarkan formula opsi jual tipe Eropa dan dengan mensubstitusikan $K=\xi^{-1}$ ke persamaan (3), diperoleh formula untuk menghitung GMMB adalah sebagai berikut.

$$
\begin{aligned}
& \pi_{M}(0)=\bar{P}_{n} p_{x}\left(e^{-r n} \Phi\left(-d_{2}(0)\right)-\right. \\
& \left.\xi \Phi\left(-d_{1}(0)\right)\right)
\end{aligned}
$$

c. Menentukan nilai opsi akhir dari GMDB.

Nilai opsi akhir dari GMDB dihitung dengan mensubstitusikan persamaan (6) ke persamaan (5) yang menghasilkan

$$
\begin{aligned}
& h(t)=\bar{P}(1-m)^{12 t} \max \left(\frac{e^{0,06 t}}{(1-m)^{12 t}}-\right. \\
& \left.S_{t}, 0\right)
\end{aligned}
$$

Harga tebus yang diperoleh yaitu $K=\frac{e^{0,06 t}}{(1-m)^{12 t}}$. Berdasarkan formula opsi jual dan dengan mensubstitusikan nilai $K$ ke dalam persamaan (4), diperoleh $v(0, t)=\bar{P}\left[\Phi\left(-d_{2}(0, t)\right)-(1-\right.$ $\left.m)^{12 t} \Phi\left(-d_{1}(0, t)\right)\right]$

d. Menghitung $d_{1}(0, t)$ dan $d_{2}(0, t)$ untuk GMMB dan GMDB berdasarkan persamaan (13).

Nilai $d_{1}(0)$ dan $d_{2}(0)$ untuk GMMB dihitung dengan mensubstitusikan $K=\xi^{-1}$ ke persamaan (13) sehingga diperoleh

$d_{1}(0)=\frac{\log (\xi)+\left(r+\frac{\sigma^{2}}{2}\right) n}{\sigma \sqrt{n}}$ $d_{2}(0)=d_{1}(0)-\sigma \sqrt{n}$.

Sebelum menghitung nilai $d_{1}(0)$, ditentukan nilai dari $\xi$ untuk $m=0 \%$ dan $2 \%$.

$$
\begin{aligned}
\xi & =(1-e)(1-m)^{n-1} \\
& =(1-0,0715)(1-0)^{45-1} \\
& =0,9285
\end{aligned}
$$

Cara yang sama digunakan untuk menghitung $\xi$ untuk $m=2 \%$.

Selanjutnya, nilai $d_{1}(0)$ dihitung sebagai berikut.

$$
\begin{aligned}
d_{1}(0) & =\frac{\log (0,9285)+\left(0,06+\frac{0,136^{2}}{2}\right) \cdot 45}{0,136 \cdot \sqrt{45}} \\
& =3,334345 . \\
d_{2}(0) & =3,334345-0,136 \cdot \sqrt{45} \\
& =2,422029 .
\end{aligned}
$$

Perhitungan $d_{1}(0)$ dan $d_{2}(0)$ untuk $m=2 \%$ dan masing-masing tingkat bunga dilakukan dengan cara yang sama.

Lebih lanjut, perhitungan $d_{1}(0, t)$ dan $d_{2}(0, t)$ untuk GMDB juga dilakukan dengan 
mensubstitusikan nilai $K=\frac{e^{0,06 t}}{(1-m)^{12 t}}$ ke dalam persamaan (13) yang menghasilkan

$$
\begin{aligned}
& d_{1}(0, t)=\frac{\log \left(\frac{(1-m)^{12 t}}{e^{0,06 t}}\right)+\left(r+\frac{\sigma^{2}}{2}\right) t}{\sigma \sqrt{t}} \\
& d_{2}(0, t)=d_{1}(0, t)-\sigma \sqrt{t}
\end{aligned}
$$

Sebagai ilustrasi, dilakukan perhitungan untuk $m=0 \%, r=6 \%$ sebagai berikut.

Untuk $t=\frac{1}{12}$,

$$
\begin{aligned}
d_{1}(0, t) & =\frac{\log \left(\frac{(1-0)^{12 \cdot \frac{1}{12}}}{e^{0,06 \cdot \frac{1}{12}}}\right)+\left(0,06+\frac{0,136^{2}}{2}\right) \cdot \frac{1}{12}}{0,136 \cdot \sqrt{\frac{1}{12}}} \\
= & \frac{\log \left(\frac{1}{1,005}\right)+(0,06+0,009248) \cdot \frac{1}{12}}{0,03926} \\
= & 0,01963 . \\
d_{2}\left(0, \frac{1}{12}\right) & =0,01963-0,136 \cdot \sqrt{\frac{1}{12}} \\
& =-0,01963
\end{aligned}
$$

untuk nilai $t$ lainnya, dihitung dengan cara yang sama.

e. Menghitung nilai distribusi normal standar.

Nilai $\Phi\left(-d_{1}(0, t)\right)$ dan $\Phi\left(-d_{2}(0, t)\right.$ untuk masing-masing garansi minimum dihitung menggunakan formula NORMDIST pada Microsoft Excel. Sebagai ilustrasi, dilakukan perhitungan untuk GMMB dengan $m=0 \%$ sebagai berikut.

$$
\begin{aligned}
\Phi\left(-d_{1}(0)\right) & =1-\operatorname{NORMDIST}(3,334345 ; 0 ; 1) \\
& =1-0,999572497 \\
& =0,000427503 . \\
\Phi\left(-d_{2}(0)\right) & =1-\operatorname{NORMDIST}(2,422029 ; 0 ; 1) \\
& =1-0,992282939 \\
& =0,007717061 .
\end{aligned}
$$

Perhitungan yang sama untuk nilai distribusi normal dengan $m=2 \%$ dan untuk masingmasing tingkat bunga. Nilai distribusi normal pada GMDB adalah sebagai berikut.

Untuk $m=0 \%, r=6 \%, t=\frac{1}{12}$,

$$
\begin{aligned}
\Phi\left(-d_{1}\left(0, \frac{1}{12}\right)\right) & =1-\operatorname{NORMDIST}(0,01963 ; 0 ; 1) \\
& =1-0,507831 \\
& =0,492169 . \\
\Phi\left(-d_{2}\left(0, \frac{1}{12}\right)\right) & =1-\operatorname{NORMDIST}(-0,01963 ; 0 ; 1) \\
& =1-0,492169 \\
& =0,507831 .
\end{aligned}
$$

Perhitungan untuk $t$ lainnya dilakukan dengan cara yang sama. f. Menghitung nilai $v(0, t)$ untuk GMDB.

Nilai $v(0, t)$ tersebut diperoleh dengan menggunakan persamaan (21) yang telah diturunkan sebelumnya. Sebagai ilustrasi untuk $m=0 \%, r=6 \%$, dan $t=\frac{1}{12}$ diperoleh

$$
\begin{aligned}
v\left(\frac{0,1}{12}\right)= & \bar{P}\left[\Phi\left(-d_{2}\left(0, \frac{1}{12}\right)\right)-\right. \\
& \left.(1-0)^{12 \cdot \frac{1}{12}} \cdot \Phi\left(-d_{1}\left(0, \frac{1}{12}\right)\right)\right] \\
= & \bar{P}(0,50783-0,49217) \\
= & 0,01566 \bar{P} .
\end{aligned}
$$

Perhitungan yang sama untuk nilai $t$ lainnya.

3. Menentukan harga premi asuransi unit link setelah diberikan garansi minimum.

a. Menghitung nilai $\pi_{M}(0)$.

Nilai GMMB, $\pi_{M}(0)$ dihitung berdasarkan persamaan (19). Sebagai ilustrasi, dilakukan perhitungan $\pi_{M}(0)$ untuk $m=0 \%$ dan $r=6 \%$ sebagai berikut.

$$
\begin{aligned}
\pi_{M}(0)= & \bar{P}_{n} p_{x}\left(e^{-r n} \Phi\left(-d_{2}(0)\right)-\right. \\
& \left.\xi \Phi\left(-d_{1}(0)\right)\right) \\
= & \bar{P} \cdot{ }_{45} p_{30} \cdot\left(e^{-0,06 \cdot 45} \cdot\right. \\
& 0,007717-0,9285 \cdot 0,0004275) \\
= & \bar{P} \cdot 0,58314 \cdot\left(e^{-2,7} \cdot\right. \\
& 0,007717-0,0003969) \\
= & 0,000121692 \bar{P}
\end{aligned}
$$

Untuk nilai $m$ lainnya dan masing-masing tingkat bunga, digunakan cara yang sama.

b. Menentukan harga premi baru untuk GMMB menggunakan persamaan (2).

Harga premi baru untuk GMMB dengan ilustrasi yang sama adalah sebagai berikut. $\bar{P}=R p 21.000 .000,00+0,000121692 \bar{P}$ $0,999878308 \bar{P}=R p 21.000 .000,00$

$$
\bar{P}=R p 21.003 .000,00 \text {. }
$$

Perhitungan yang sama untuk $m$ dan tingkat bunga lainnya. Harga premi selengkapnya ditampilkan dalam tabel berikut.

Tabel 1. Harga Premi Setelah Disertai GMMB

\begin{tabular}{|c|c|c|}
\hline & \multicolumn{2}{|c|}{$m$} \\
\hline$r$ & $0 \%$ & $2 \%$ \\
\hline $6 \%$ & $\operatorname{Rp} 21.003 .000,00$ & $\mathrm{Rp} \mathrm{21.031.000,00}$ \\
\hline $14 \%$ & $\mathrm{Rp} 21.000 .000,00$ & $\mathrm{Rp} \mathrm{21.000.000,00}$ \\
\hline $20 \%$ & $\mathrm{Rp} 21.000 .000,00$ & $\mathrm{Rp} 21.000 .000,00$ \\
\hline
\end{tabular}

Sumber: Data Diolah (2019) 
Harga premi untuk tingkat bunga $14 \%$ dan $20 \%$ baik dengan biaya pengelolaan $0 \%$ maupun $2 \%$ tidak mengalami perubahan karena nilai $\pi_{M}(0)$ yang diperoleh adalah 0 . Hal ini diakibatkan nilai dari $e^{-r n}$ menuju 0 .

c. Menentukan peluang kematian yang tertunda, $\left.{ }_{t-\frac{1}{12}}\right|_{\frac{1}{12}} q_{x}$.

Peluang kematian tertunda dapat dihitung sebagai berikut.

$$
\begin{aligned}
& t-\left.\frac{1}{12}\right|_{\frac{1}{12}} q_{x}={ }_{t-\frac{1}{12}} p_{x}-\left(t-\frac{1}{12}\right)+\frac{1}{12} p_{x} \\
& \left.\Leftrightarrow{ }_{t-\frac{1}{12}}\right|_{1} q_{x}={ }_{t} q_{x}-{ }_{t-\frac{1}{12}} q_{x} .
\end{aligned}
$$

Untuk $t=\frac{1}{12}$,

$$
\begin{aligned}
\frac{1}{12}-\left.\frac{1}{12}\right|_{\frac{1}{12}} q_{30} & ={ }_{\frac{1}{12}} q_{30}-\frac{1}{12}-\frac{1}{12} q_{30} \\
& =\frac{1}{12} q_{30}-{ }_{0} q_{30} \\
& =0,0000633-0 \\
& =0,000063 .
\end{aligned}
$$

Nilai peluang kematian tertunda untuk $t$ yang lain diperoleh dengan cara yang sama.

d. Menghitung nilai $\pi_{D}(0)$.

Nilai GMDB dihitung menggunakan persamaan (8). Sebagai ilustrasi, akan ditentukan nilai $\pi_{D}(0)$ untuk $m=0 \%$ dan $r=6 \%$ sebagai berikut.

$$
\begin{aligned}
\pi_{D}(0)= & \sum_{t=\frac{1}{12}}^{\frac{12 n}{12}} v(0, t)_{t-\frac{1}{12}} \mid \frac{1}{12} q_{x} \\
= & 0,01566 \bar{P} \cdot 0,0000633+ \\
& 0,02215 \bar{P} \cdot 0,0000633+\cdots+ \\
& 0,35172 \bar{P} \cdot 0,0039058 \\
= & 0,16441242 \bar{P} .
\end{aligned}
$$

Nilai GMDB untuk masing-masing tingkat bunga dan $m$ lainnya dihitung dengan cara yang sama.

e. Menentukan harga premi asuransi baru untuk GMDB menggunakan persamaan (7).

Menggunakan ilustrasi yang sama, harga premi baru yang disertai dengan GMDB dapat dihitung sebagai berikut.

$$
\begin{aligned}
& \bar{P}=P+\pi_{M}(0) \\
& \bar{P}=R p 21.000 .000,00+0,16441242 \bar{P} \\
& 0,83558758 \bar{P}=R p 21.000 .000,00 \\
& \bar{P}=R p 25.132 .000,00 .
\end{aligned}
$$

Harga premi baru untuk asuransi unit link yang disertai dengan GMDB ditampilkan dalam tabel berikut ini.
Tabel 2. Harga Premi Setelah Disertai GMDB

\begin{tabular}{|c|c|c|}
\hline & \multicolumn{2}{|c|}{$m$} \\
\hline$r$ & $0 \%$ & $2 \%$ \\
\hline $6 \%$ & $\operatorname{Rp~25.132.000,00~}$ & $\operatorname{Rp~44.521.000,00~}$ \\
\hline $14 \%$ & $\operatorname{Rp~21.031.000,00~}$ & $\operatorname{Rp~44.520.000,00~}$ \\
\hline $20 \%$ & $\operatorname{Rp} 21.002 .000,00$ & $\operatorname{Rp~44.520.000,00~}$ \\
\hline
\end{tabular}

Sumber: Data Diolah (2019)

\section{KESIMPULAN DAN SARAN}

Kesimpulan yang diperoleh dari penelitian ini, yaitu nilai GMMB hanya didapatkan untuk tingkat bunga $6 \%$. Tingkat bunga $14 \%$ dan $20 \%$ baik untuk $m=0 \%$ maupun $m=2 \%$ menghasilkan nilai GMMB sama dengan 0 , sehingga harga premi tunggal yang dibayarkan tidak mengalami perubahan. Hal ini diakibatkan oleh nilai $e^{-r n}$ untuk $r=14 \%$ dan $r=20 \%$ menuju 0. Di lain pihak, dalam perhitungan GMDB terlihat bahwa harga premi untuk masing-masing biaya pengelolaan cenderung berada pada rentangan yang sama. Dengan demikian, dalam GMMB faktor yang lebih memengaruhi harga premi adalah tingkat bunga yang dipilih, sedangkan besarnya biaya pengelolaan dana pemegang polis lebih berpengaruh dalam perhitungan GMDB. Dari kedua jenis garansi minimum yang ditawarkan tersebut, dalam kasus ini GMDB akan memberikan keuntungan lebih banyak kepada pemegang polis. Hal ini dikarenakan nilai garansi yang diberikan dihitung setiap bulannya sepanjang kontrak.

Untuk penelitian selanjutnya mengenai garansi minimum, penulis menyarankan untuk melakukan perhitungan jenis garansi lainnya. Selanjutnya, untuk penelitian di bidang yang sama, penulis menyarankan untuk meneliti pengaruh usia, jangka waktu kontrak atau faktor lain yang dapat memengaruhi harga premi baru yang akan dihasilkan.

\section{DAFTAR PUSTAKA}

Cristina, C. \& Diana-Maria, C. 2014. Pricing and Assessing Unit-Linked Insurance Contracts With Investment Guarantees. Annals of The University of Oradea, Economic Science Series, Vol. 1, p. 865 https://www.google.com/url?sa=t\&source=we b\&rct=j\&url=http://steconomiceuoradea.ro/an ale/volume/2014/n1/095.pdf\&ved=2ahUKEwj Tv7Glv97gAhUMeisKHQz- 


\section{CVUQFjACegQIBBAB\&usg=AOvVaw0WV LHAzQj7xxoF7a2Xf0Uj}

Dickson, D., Hardy M, M. \& Waters, H. 2009. Actuarial Mathematics and Contingent Risks. $1^{\text {st }}$ ed. Cambridge: Cambridge University Press.

Hardy, M. 2003. Investment Guarantees : Modeling and Risk Management for Euqity-
Linked Life Insurance. New Jersey: John Wiley \& Sons, Inc..

Rayvin, M. 2015. Menentukan Premi dan Nilai Discounted Future Cost pada Asuransi Jiwa Unit Link. Jurnal Matematika, Aplikasi, dan Pembelajarannya, Vol. 14, p. 30. 